\title{
Acute post-streptococcal glomerulonephritis - immune-mediated acute kidney injury - case report and literature review
}

\author{
PIOTR SKRZYPCZYK ${ }^{1}$ ANNA OFIARA ${ }^{1}$, ANNA ZACHARZEWSKA ${ }^{2}$, \\ MAEGORZATA PAŃCZYK-TOMASZEWSKA ${ }^{l}$ \\ ${ }^{1}$ Department of Pediatrics and Nephrology, Medical University of Warsaw, Poland \\ ${ }^{2}$ Student Scientific Group at the Department of Pediatrics and Nephrology, Medical University of Warsaw, Poland
}

\begin{abstract}
Acute post-streptococcal glomerulonephritis (APSGN) is an immunological complication of infection with group A $\beta$-hemolytic streptococcus (GAS). The disease manifests as microscopic or gross hematuria, arterial hypertension, edema, and acute kidney injury and has most commonly a self-limiting course. We report a very severe case of APSGN in a 5-year-old girl with superimposed generalized infection. The girl presented significant overhydration, a very low glomerular filtration rate (GFR) $\left(11.2 \mathrm{ml} / \mathrm{min} / 1.73 \mathrm{~m}^{2}\right)$, hyperuricemia $(12.7 \mathrm{mg} / \mathrm{dl})$, nephrotic proteinuria, and gross hematuria. Her immunological tests allowed for the diagnosis of APSGN (elevated antistreptolysin O [ASO] titer, low C3, and normal C4 complement factors). She also showed very high inflammatory indicators suggestive of sepsis. She received supportive treatment together with ceftriaxone and a single dose of rasburicase. Her renal function recovered, and urinalysis normalized. Gallbladder deposits complicated the treatment. This article summarizes the existing knowledge on APSGN with particular emphasis on the immunological mechanisms of the disease. The proposed immunological pathway leading to glomerular injury is discussed. In children, APSGN has an excellent prognosis, including in cases with severe renal impairment in the early stages of the disease.
\end{abstract}

Key words: children, acute post-streptococcal glomerulonephritis, nephritic syndrome, group A streptococcus (GAS), nephritis-associated plasmin receptor (NAPlr), streptococcal pyrogenic exotoxin $B$ (SPE B).

(Cent Eur J Immunol 2021; 46 (4): 516-523)

\section{Introduction}

Acute post-streptococcal glomerulonephritis (APSGN) is a renal immunological complication of an infection caused by nephritogenic strains of group A $\beta$-hemolytic streptococci (GAS, Streptococcus pyogenes). Approximately 500,000 new cases of APSGN are diagnosed each year, with over $90 \%$ in low-socioeconomic-status regions, with an incidence reaching $28.5 / 100,000$ of the pediatric population/year [1-3]. In the developed countries, a systematic decrease in disease incidence is observed with an estimated incidence (based on Italian data) of 0.3/100,000 of the pediatric population/year [4]. The disease occurs twice as often in boys, most frequently in children between 5 and 12 years of age and after 60 years [2].

Symptoms appear after a latency period after streptococcal infection of 1-3 weeks (streptococcal tonsillitis, scarlet fever) or 3-6 weeks (erysipelas or impetigo) [2, 3].
Clinically, the disease manifests as a nephritic syndrome of varying severity (microscopic or gross hematuria, usually non-nephrotic proteinuria, acute kidney injury [AKI], edema, arterial hypertension), although it may also present as incidentally diagnosed asymptomatic hematuria $[3,5]$. The diagnosis is based on the history, typical clinical course, and characteristic pattern of abnormalities in blood tests: elevated antistreptolysin O (ASO) and decreased C3 component of the complement system. Treatment is symptomatic (salt-restricted diet, fluid restriction, hypotensive treatment, rarely renal replacement therapy) [3]. The prognosis in APSGN is usually excellent, with no distant renal sequelae of the disease in most patients [2].

The exact immunological mechanism of the disease is not fully explained yet, and in situ formation of immune complexes containing streptococcal antigen is the most likely pathogenesis. The complexes activate the alternative complement pathway and lead to local glomerular inju-

Correspondence: Piotr Skrzypczyk, MD, PhD, Department of Pediatrics and Nephrology, Medical University of Warsaw, Poland,

e-mail: pskrzypczyk@wum.edu.pl

Submitted: 6.09.2021; Accepted: 2.12.2021 
ry. This manuscript aims to present a very severe case of APSGN and summarize current knowledge on the disease, emphasizing immunological mechanisms.

\section{Case report}

We present a case of a girl aged five years and ten months admitted to our department with AKI. She presented with weakness, apathy, fever, and vomiting for four days. She did not want to eat or drink, and due to fever, she received acetaminophen (suppositories) $15 \mathrm{mg} / \mathrm{kg}$ / dose once daily. On the day of admission, she passed only a small amount of urine in the morning. In addition, she had a history of vulvitis a few days before hospital admission and a history of symptomatically treated respiratory tract infection with a sore throat two weeks before.

The pregnancy was complicated by hyperthyroidism, glucose intolerance, premature uterine contractions, maternal infection in the $34^{\text {th }}$ week of gestation, and fetal distress. The girl was born in the $35^{\text {th }}$ week of pregnancy by cesarean section, and congenital pneumonia, sepsis, intracerebral hemorrhage I/II, and hypothyroidism complicated the perinatal period. The girl remained under endocrinological care and received L-thyroxin in the dose of $12.5 \mu \mathrm{g}$ daily. Except for varicella eight months before, she did not have any other serious diseases after the neonatal period. She had normal development and received vaccinations according to the Polish schedule. The family history was unremarkable.

The tests taken in an emergency department revealed leukocytosis $21 \times 10^{3} / \mu \mathrm{l}, \mathrm{C}$-reactive protein $(\mathrm{CRP})$
$11.5 \mathrm{mg} / \mathrm{dl}$ (normal value $<0.5$ ), procalcitonin $1.93 \mathrm{ng} / \mathrm{ml}$, urea $180 \mathrm{mg} / \mathrm{dl}$, creatinine $4.3 \mathrm{mg} / \mathrm{dl}$ (glomerular filtration rate [GFR] according to Schwartz formula $11.2 \mathrm{ml} / \mathrm{min} / 1.73 \mathrm{~m}^{2}$ [6]), ultrasonography showed kidneys of normal size (right kidney 89 mm, left kidney $93 \mathrm{~mm}$ ), with normal corticomedullary differentiation and increased echogenicity. The girl received $500 \mathrm{ml}$ of intravenous (iv) fluid (5\% glucose + saline), one dose of ceftriaxone $(70 \mathrm{mg} / \mathrm{kg} / \mathrm{dose})$ and was admitted to our nephrology department.

On admission, the girl was in average general condition, apathetic. Physical examination revealed foot and ankle edema, sore throat, symmetrical, swollen tonsils without exudate, normal chest examination, bloated abdomen, and vulvitis. Her height was $117 \mathrm{~cm}$, her weight was $21.4 \mathrm{~kg}$ (pre-disease weight approx. $20 \mathrm{~kg}$ ), blood pressure $115 / 71 \mathrm{~mm} \mathrm{Hg}$, heart rate $80 / \mathrm{min}$, respiratory rate $20 / \mathrm{min}$, temperature $37.3^{\circ} \mathrm{C}$. Her laboratory tests in the department are shown in Table 1. The heart and lung X-ray images were normal. The girl received a fluid bolus $(250 \mathrm{ml})$, glucose with insulin, furosemide $50 \mathrm{mg}$ iv. The first urine sample was passed 6 hours after the admission. The urine was cloudy, with proteinuria $543 \mathrm{mg} / \mathrm{dl}$, leukocytes, and erythrocytes completely covering the visual field. The immunological tests were as follows: elevated ASO titer, decreased C3, normal C4 and immunoglobulin levels [IgA - $134 \mathrm{mg} / \mathrm{dl}$ (n: 28-235), IgG - $938 \mathrm{mg} / \mathrm{dl}$ (n: 853-1440), IgM - 93.1 (n: 36-198)]. The girl was diagnosed with APSGN. During the first days, she required intravenous furosemide to maintain fluid balance. A low-salt and low-potassium diet were implemented. Ion-exchange resins were

Table 1. Laboratory results in the patient with acute post-streptococcal glomerulonephritis

\begin{tabular}{|c|c|c|c|c|c|c|c|}
\hline Parameter & Day 1 & Day 2 & Day 3 & Day 4 & Day 6 & Day 10 & Day 13 \\
\hline $\mathrm{WBC}\left[10^{3} / \mu \mathrm{l}\right]$ & 18.44 & 17.85 & 14.68 & 13.09 & 10.32 & 13.25 & 15.13 \\
\hline Hemoglobin $[\mathrm{g} / \mathrm{dl}]$ & 10.3 & 11.2 & 11.4 & 10.4 & 10.3 & 9.5 & 9.5 \\
\hline $\mathrm{CRP}[\mathrm{mg} / \mathrm{dl}]$ & 18.2 & & 8.9 & 6.4 & 4.6 & 1.4 & $<0.5$ \\
\hline PCT & 2.77 & & & 0.70 & 0.19 & $<0.05$ & $<0.05$ \\
\hline Creatinine $[\mathrm{mg} / \mathrm{dl}]$ & 4.1 & 3.7 & 2.9 & 1.9 & 1.1 & 0.7 & 0.6 \\
\hline Urea $[\mathrm{mg} / \mathrm{dl}]$ & 183 & 177 & 178 & 156 & 96 & 21 & 25 \\
\hline Uric acid [mg/dl] & 12.7 & 12.7 & $<0.5$ & & & 4.4 & 5.6 \\
\hline GFR $\left[\mathrm{ml} / \mathrm{min} / 1.73 \mathrm{~m}^{2}\right]$ & 11.8 & 13.1 & 16.7 & 25.4 & 43.9 & 69.0 & 80.5 \\
\hline Albumin [g/dl] & 3.0 & & & 2.8 & & 3.3 & 4.0 \\
\hline Potassium [mmol/1] & 6.0 & 5.3 & 5.4 & 4.5 & 4.1 & 4.3 & 4.8 \\
\hline $\mathrm{C} 3[\mathrm{mg} / \mathrm{dl}]^{1}$ & 25.5 & & & & & 73.6 & 103.0 \\
\hline $\mathrm{C} 4[\mathrm{mg} / \mathrm{dl}]^{2}$ & 21.9 & & & & & 27.4 & 28.3 \\
\hline $\mathrm{ASO}[\mathrm{IU} / \mathrm{ml}]^{3}$ & 401 & & & & & 719 & 760 \\
\hline Proteinuria [mg/dl] & & 534 & & 412 & & 239 & 389 \\
\hline
\end{tabular}


administered, and ceftriaxone was continued due to very high inflammatory markers. Because of severe hyperuricemia, she received a single dose of rasburicase $(0.2 \mathrm{mg} / \mathrm{kg} /$ dose iv), which resulted in a significant drop in serum uric acid concentration. The child's condition improved, and overhydration disappeared in the following days. In laboratory tests, renal function parameters gradually decreased, inflammatory markers and ions normalized, and slight anemia persisted. In urine examination, decreasing proteinuria was observed. Arterial blood pressure periodically rose to $125 / 75 \mathrm{~mm} \mathrm{Hg}$ but normalized completely during the hospitalization. On the $12^{\text {th }}$ day in the evening, severe colicky pain in the mediastinum occurred. The ultrasound examination showed a deposit $(22 \times 11 \mathrm{~mm})$ in the gallbladder. The deposit was most likely related to the administration of ceftriaxone. A pediatric gastroenterologist consulted the child and recommended further observation. On the day of the discharge, she presented in good condition, without edema (body weight $19.7 \mathrm{~kg}$ ), in morphology there was persistent anemia, her kidney function improved significantly, and her ions normalized; her transaminases and bilirubin were normal, and her $\gamma$-glutamyl transaminase was slightly elevated [23 U/1 (n: 8-18)]. She was discharged home with persistent proteinuria.

In further follow-up, her kidney function normalized six weeks after the disease onset (creatinine $-0.4 \mathrm{mg} / \mathrm{dl}$, glomerular filtration rate [GFR] $120.8 \mathrm{ml} / \mathrm{min} / 1.73 \mathrm{~m}^{2}$ ), urinalysis normalized within six months, and gallbladder deposits disappeared after three months. She had no recurrences of the disease.

\section{Discussion}

We reported the clinical course of a very severe case of APSGN. The girl presented with unusually high parameters of kidney function. She did not require renal replacement therapy despite an initial GFR below $15 \mathrm{ml} / \mathrm{min} / 1.73 \mathrm{~m}^{2}$ as her kidney function improved spontaneously. AKI with severe overhydration, hypertension or hyperkalemia indicates acute dialysis; however, this is extremely rare in children with APSGN. Interestingly, the girl presented with high inflammatory markers, suggestive of generalized infection, which does not fit the picture of post-infectious glomerulonephritis. Most likely, her AKI was of mixed etiology: APSGN and superimposed sepsis.

APSGN can occur in sporadic and epidemic forms and is more common in spring or autumn, associated with a higher incidence of streptococcal infections [3]. GAS is classified as different serotypes depending on the M protein present in the cell membrane [7]. Seegal and Earle postulated already in the early 1940s that only certain types of streptococci can cause glomerulonephritis. The types responsible for glomerulonephritis are called "nephritogenic". The risk of APSGN in case of infection caused by nephritogenic GAS reaches $15 \%$ [3]. Different types of
S. pyogenes cause APSGN followed by pharyngitis, tonsillitis or scarlet fever (types 1, 2, 3, 4, 6, 12, 18, 19, 24, $25,31,49)$ and other types followed skin infection such as roseola or impetigo (types $49,55,56,57,60$ ) $[2,3,5,8]$. It is unclear what determines the potential of only certain streptococcal serotypes to cause APSGN. Streptococcal pharyngitis precedes APSGN more often than dermatitis [1], and serotypes 1, 4 and 12 are responsible for $90 \%$ of all APSGN cases [2, 3, 8]. It is worth noting that epidemic cases of APSGN are usually reported after cutaneous infections [2,9]. It should be emphasized that many cases of the disease are barely symptomatic or even subclinical - in epidemic cases, this may concern as many as $80 \%$ of all cases $[10,11]$. Therefore, in our opinion, it is reasonable to routinely order a urinalysis after a streptococcal infection taking into account the latency period.

Literature data indicate a twofold higher incidence of APSGN in boys [11]. Although the disease can occur at any age, including in adults (about $10 \%$ of cases), it is rarely found in children younger than three years of age, with only isolated reports of patients in the $1^{\text {st }}$ year of life [12]. The smaller pore size in the glomerular basement membrane (GBM) in children, which hinders the renal removal of immune complexes, may be responsible for the higher incidence of APSGN in the pediatric population. On the other hand, the low incidence in the first two years of life may result from a lower frequency of streptococcal infections, the immune system's immaturity, and lower ability to form immune complexes in this group of patients $[2,13]$.

Macroscopic hematuria, edema, and arterial hypertension are the most prevalent clinical signs of APSGN, observed in approximately $30-50 \%, 70 \%$, and $50-90 \%$ of the patients, respectively $[2,3,11]$. Nephrotic-range proteinuria is uncommon, observed in approximately $2-5 \%$ of cases [3, 14]. Both edema and hypertension result from renal sodium and water retention. In the literature, there are rare cases of acute circulatory failure with pulmonary edema.

Interestingly, reversible systolic or diastolic cardiac dysfunction is present in up to $20 \%$ of children with APSGN [15]. Occasionally, there may be a sudden increase in blood pressure with encephalopathy manifesting as severe headaches, vomiting, visual disturbances, and seizures [16]. Our patient presented with severe overhydration (almost $10 \%$ of normal body weight) but without evident circulatory insufficiency or pulmonary congestion features. She did not have sustained hypertension either.

Though the disease has been known for decades, the exact immunological mechanism is still unclear. APSGN belongs to the group of post-infectious glomerulopathies (PIGN). It is by far the most common form of this disease, although the condition may be a consequence of other bacterial, viral, or even parasitic infections (Table 2). Non-streptococcal PIGN is found nowadays more commonly in adults, in developed countries, and generally has 
Table 2. Microorganisms that may cause acute post-infectious glomerulonephritis according to [2, 3, 14, 41-43]

\begin{tabular}{|c|c|c|c|}
\hline \multicolumn{4}{|c|}{ Microorganism } \\
\hline Bacteria & Viruses & Fungi & Parasites \\
\hline Streptococcus gr. A (pyogenes), $C, G$ & Coxsackie & Candida spp. & Plasmodium malariae \\
\hline Streptococcus pneumoniae & $\mathrm{ECHO}$ & Coccidioides immitis & Plasmodium falciparum \\
\hline Streptococcus viridians & Cytomegalovirus & Histoplasma capsulatum & Schistosoma mansoni, \\
\hline Staphylococcus (aureus, epidermidis, albus, & Epstein-Barr & & japonicum, haematobium \\
\hline haemolyticus, equi) & Hepatitis $B$ and $C$ & & Toxoplasma gondii \\
\hline Neisseria meningitides & Human & & Wuchereria bancrofti \\
\hline Neisseria gonorrhoeae & immunodeficiency virus & & Brugia malayi \\
\hline Salmonella typhi, paratyphi, typhimurium & Influenza viruses & & Loa loa \\
\hline Klebsiella pneumoniae & Parainfluenza viruses & & Onchocerca volvulus \\
\hline Escherichia coli & Adenoviruses & & Trichinella spiralis \\
\hline Acinetobacter spp. & Rubella virus & & Trypanosoma cruzi, brucei \\
\hline Serratia spp. & Measles virus & & Leishmania donovani \\
\hline Proteus spp. & Chickenpox virus* & & Toxocara canis, cati \\
\hline Pseudomonas spp. & Parvovirus B19 & & Strongyloides stercoralis \\
\hline Haemophilus influenzae & Mumps virus & & \\
\hline \multicolumn{4}{|l|}{ Mycobacterium tuberculosis, avium, leprae } \\
\hline \multicolumn{4}{|l|}{ Yersinia enterocolitica } \\
\hline \multicolumn{4}{|l|}{ Legionella pneumoniae } \\
\hline \multicolumn{4}{|l|}{ Mycoplasma pneumoniae } \\
\hline \multicolumn{4}{|l|}{ Brucella melitensis } \\
\hline \multicolumn{4}{|l|}{ Treponema pallidum } \\
\hline \multicolumn{4}{|l|}{ Corynebacterium bovis } \\
\hline \multicolumn{4}{|l|}{ Corynebacterium diphtheriae } \\
\hline \multicolumn{4}{|l|}{ Campylobacter spp. } \\
\hline \multicolumn{4}{|l|}{ Actinobacillus spp. } \\
\hline \multicolumn{4}{|l|}{ Bartonella henselae } \\
\hline \multicolumn{4}{|l|}{ Coxiella burnetii } \\
\hline \multicolumn{4}{|l|}{ Leptospira spp. } \\
\hline \multicolumn{4}{|l|}{ Brucella spp. } \\
\hline \multicolumn{4}{|l|}{ Listeria monocytogenes } \\
\hline \multicolumn{4}{|l|}{ Orientia tsutsugamushi } \\
\hline Aggregatibacter actinomycetemcomitans & & & \\
\hline
\end{tabular}

worse outcomes [14]. Most pathophysiological data are available for APSGN. There are five main mechanisms proposed to explain the immunologic glomerular injury induced by GAS infection: deposition of circulating immune complexes containing streptococcal antigens, in situ immune complex formation resulting from deposition of streptococcal antigens within the GBM, and subsequent antibody binding, in situ glomerular immune complex formation promoted by antibodies to streptococcal antigens that cross-react with glomerular components (molecular mimicry), activation of the alternative pathway of complement due to the transient presence of autoantibodies against factor $\mathrm{B}$, and finally autoimmunological reaction $[3,14,17,18]$.

There is some experimental and clinical evidence supporting the autoimmune reactivity theory. Firstly, antiimmunoglobulin $\mathrm{G}(\mathrm{IgG})$ reactivity has been revealed in subjects with APSGN. For example, anti-IgG glomerular deposits were detected in renal biopsy specimens, and anti-IgG activity was found in eluates from the kidney of a patient with a fatal course of APSGN [3]. Burova et al. reported that nephritogenic strains of Streptococcus produce IgG Fc binding proteins (IgGFcBPs) and may stimulate the production of anti-IgG antibodies [19]. In addition, streptococcal neuraminidase was found to modify human immunoglobulins (reveal or create hidden antigens or epitopes), which triggers the production of antibodies directed against them. Rodriguez-Iturbe found neuraminidase activity and free neuraminic acid in the serum of patients with APSGN, and this finding was specific for this entity [20]. Also, some patients may have different auto-antibodies such as antinuclear antibodies (ANA), anti-dsDNA, anti-C1q antibodies, antineutrophil cytoplasmic antibodies (ANCA), and rheumatic factor (RF), which suggests non-specific autoimmune reactivity [21]. The pathogenetic role of these autoantibodies is unclear.

The most plausible theory, confirmed by numerous experimental animal studies, is that the immune complexes that form in situ in glomeruli cause APSGN [3, 22]. These complexes contain a streptococcal antigen and immunoglobulins G directed against them. Nephritis-associated plasmin receptor (NAPlr) and streptococcal pyrogenic 


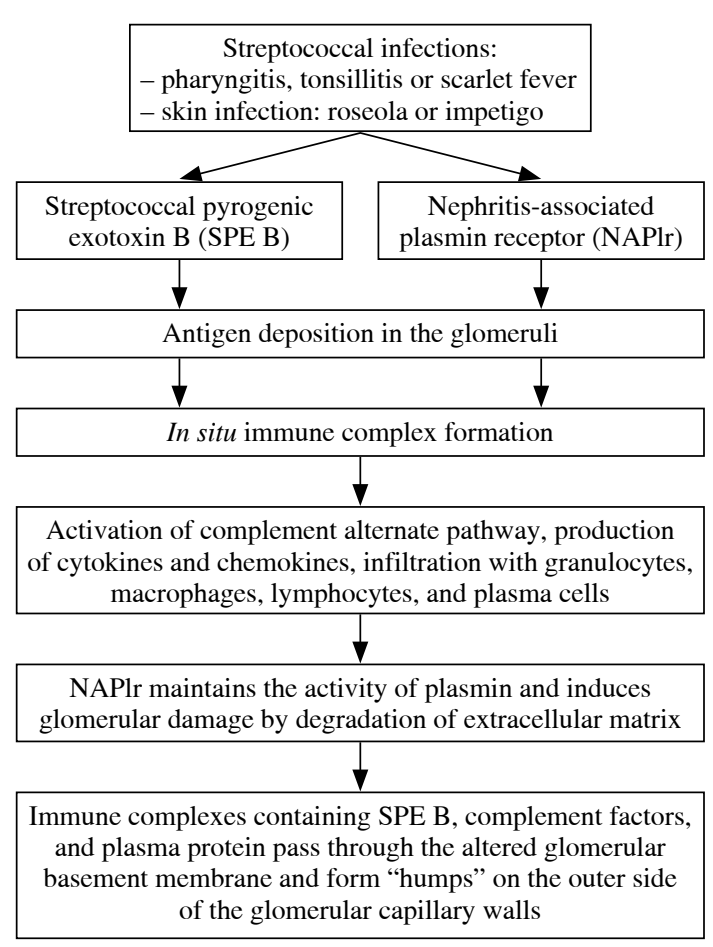

Fig. 1. The proposed pathogenesis of acute post-streptococcal glomerulonephritis according to [14, 23, 24]

exotoxin B (SPE B) are the most commonly proposed "nephritogenic antigens". Also, other streptococcal proteins were suggested as possible triggering antigens, i.e., endostreptosin (ESS), preabsorptive antigen, and nephritogenic-strains associated protein [2, 3, 14]. The isolation of SPE B and NAPlr and antibodies directed against them simultaneously from serum and renal biopsies of patients with APSGN makes them the most serious candidates for the nephritogenic toxin.

NAPlr is a glycolytic enzyme with glyceraldehyde-3-phosphate dehydrogenase (GAPDH) and plasmin-like activities $[23,24]$. The latter may play a vital role in a glomerular inflammatory reaction, as elevated urinary plasmin activity was found in patients with APSGN [25]. Japanese authors revealed that in kidney biopsy specimens from patients with APSGN, NAPlr was observed mainly in the early stage of the disease (the first two weeks) but was not colocalized with either $\mathrm{C} 3$ or IgG. In addition, the authors analyzed the presence of anti-NAPlr antibodies in sera of patients with APSGN, in patients with GAS infection but without glomerulonephritis, and in healthy volunteers. Anti-NAPlr antibodies were present most frequently in subjects with APSGN, and antibody titers were significantly higher than in patients with streptococcal infection or in the control group. Moreover, antibody titers remained elevated during the entire 10-year follow-up period [23].

SPE B has a cationic cysteine proteinase and was found in subepithelial deposits (humps) of biopsied pa- tients with APSGN [26]. Batsford et al. found SPE B in 12 out of 17 kidney biopsy specimen colocalized with complement deposition within the humps. In this study, antibodies to SPE B were detected in sera of all 53 patients who were tested. In contrast, in this patient cohort, antibodies to NAPlr were found in only 5 of 47 tested sera and only one biopsy sample [27]. Interestingly, Batsford's study included only patients from Latin America and Switzerland. An interesting theory is that various antigens trigger APSGN in different parts of the world or patients with diverse genetic backgrounds $[3,18]$. It is also possible that both these antigens play a role in the pathogenesis of APSGN - NAPlr maintains plasmin activity and other streptococcal enzymes (streptokinase, enolase) induce damage to the GBM. Consequently, immune complexes containing SPE B, complement factors, and plasma protein pass through the damaged membrane to form subepithelial humps.

Both SPE B and NAPlr can activate the complement system through an alternative pathway (as evidenced by lowered C3 and normal C4 component levels) and lead to the development of local inflammation by starting chemotaxis and interleukin- 6 production by mesangial cells and expression of adhesion molecules on the endothelium [23, $27,28]$. A decrease in complement component $\mathrm{C} 3$ is found in $78-96 \%$ of patients $[2,3]$. SPE B is also a superantigen capable of activating $\mathrm{T}$-cells without antigen-presenting cells [14]. A decrease in C4 has also been described in the literature. It is explained by activating the classical pathway of complement in some patients by circulating immune complexes containing streptococcal antigens [29]. In APSGN, complement may also be activated through the lectin pathway [14]. An increase in IgA and IgG immunoglobulin levels was also found in some patients with APSGN $[2,30]$. A summary of the proposed immunological mechanism of APSGN is presented in Figure 1.

Recently, a novel mechanism of complement activation was proposed. Chauvet et al. found autoantibodies against factor B (a component of the alternative pathway C3 convertase) in 31 out of 34 children with APSGN. Antifactor B autoantibodies were transient and correlated with plasma C3 and soluble C5b-9 levels. The authors also demonstrated that anti-factor B antibodies enhance alternative pathway convertase activity in vitro, confirming their pathogenic effect. Interestingly, anti-factor B antibodies were absent in children with C3 glomerulopathy - another disease with activation of the alternative complement pathway. In the authors' opinion, at the onset of a nephritic syndrome with a low C3 level, screening for anti-factor B antibodies might help guide indications for kidney biopsy to avoid misdiagnosed C3 glomerulopathy [31].

The genetic backgrounds that predispose to APSGN are still unclear, but they may explain a greater susceptibility to the disease in some families. Studies focused mainly on human leukocyte antigen (HLA) class II genes, which are crucial in the antigen presentation process. 
Table 3. Biochemical and immunological anomalies found in patients with acute post-streptococcal glomerulonephritis $[3,14,17]$

\begin{tabular}{lc}
\hline Abnormality & Duration \\
\hline Macroscopic hematuria & Up to 3 weeks \\
\hline Urinalysis disturbances & Usually up to 6 months \\
\hline Proteinuria & Usually up to 12 months, sometimes 24 months or longer \\
\hline Erythrocyturia & Usually up to 6 weeks, sometimes up to 6 months \\
\hline Low complement factor 3 & Few weeks to few months \\
\hline Elevated antistreptolysin A (ASO) serum titer & 7-10 days (sometimes up to 4 weeks) \\
\hline Elevated serum creatinine and lowered glomerular filtration rate &
\end{tabular}

Table 4. Differential diagnosis of nephritic syndrome (classifications based on typical course)

\begin{tabular}{ll}
\hline Low complement factors & \multicolumn{1}{c}{ Normal complement factors } \\
\hline - Acute poststreptococcal glomerulonephritis & - IgA nephropathy \\
- Other post-infectious glomerulonephritis & - IgA vasculitis nephritis (former name: Henoch-Schönlein nephritis) \\
- Membranoproliferative glomerulonephritis and & - ANCA-associated vasculitis \\
C3 glomerulopathy & - anti-GBM disease (Goodpasture disease) \\
- Lupus nephritis & - Membranous nephropathy \\
- Shunt-nephritis & \\
- Cryoglobulinemia & \\
- Glomerulonephritis associated with infectious endocarditis & \\
\hline ANCA - anti-neutrophil cytoplasm antibodies, GBM-glomerular basement membrane
\end{tabular}

Bakr et al. found that Egyptian children with the allele HLADRB 1*03011 or HLA-DRB1*1105 had an increased risk of developing APSGN [10]. On the other hand, Mori et al. found no correlation with any HLA-DRB 1 allele, but a significant risk of APSGN was found in Japanese children with HLA-DP5 (HLA-DPA $1 * 02022$ and HLADPB1*0501) [32].

Renal biopsy is not a standard diagnostic procedure and is only performed if another glomerulopathy is suspected. In light microscopy, the lesions are generalized and diffuse. Enlargement of glomeruli with the proliferation of endothelial and mesangial cells and numerous inflammatory cells (mainly neutrophils, but also macrophages, lymphocytes, and plasma cells) infiltrating the glomerular vessels and mesangium are characteristic features of APSGN. The accumulation of inflammatory cells in the vascular bundle and the fibrin deposits causes glomeruli enlargement and filling of Bowman's space. The vascular endothelial cells are swollen, and the capillary lumen narrows. As the patient heals, the number of granulocytes decreases, and the lumen of the capillaries become more visible. The proliferation of mesangial cells lasts the longest. Immunofluorescence examination reveals irregular granular deposits of complement components and antibodies located along the walls of glomerular capillaries, less frequently in the mesangium. IgG and $\mathrm{C} 3$ deposits are most commonly seen. Less commonly, C4, C1q, IgM, fibrinogen, and factor $\mathrm{B}$ are detected. The scattered distribution of $\mathrm{C} 3$ deposition in the capillary wall gives a "starry sky" pattern. In electron microscopy, electron-dense domeshaped subepithelial granular deposits (humps) are the most characteristic feature. IgG class antibodies, C3 component, and streptococcal toxin SPE B were detected in the humps. Humps, although characteristic for APSGN, are not pathognomonic for this disease because they are sometimes observed in other entities with glomerular deposition of immune complexes, e.g., lupus nephropathy. Electron microscopy may also reveal granular deposits within the mesangium and subendothelial space [2, 3, 14, 17].

The diagnosis of streptococcal etiology is confirmed by the elevated titer of antistreptolysin O (ASO), which is found in virtually all children after a throat infection and $30-50 \%$ after a skin infection [7]. In children with skin infections, the determination of anti-deoxyribonuclease B (anti-DNase B), anti-hyaluronidase (AHase), or anti-nicotinamide adenine dinucleotidase antibodies (anti-NADase) is more practical $[2,3]$. The titer of the serological markers increases from the seventh day after the infection, reaching a peak around day 30, but returns to the normal range after about 3-4 months [33]. Serological tests for a history of streptococcal infection should be performed as they have a higher sensitivity than a history of a recent infection or positive throat, nose, or skin cultures [2, 17]. Table 3 presents biochemical and immunological abnormalities typical for APSGN with a literature-based duration of normalization. The differential diagnosis of the causes of the nephritic syndrome included (Table 4), e.g., membranoproliferative glomerulonephritis (including a recently sepa- 
rated disease entity - C3 nephropathy), rapidly progressive glomerulonephritis, lupus nephropathy, and other forms of post-infectious glomerulonephritis (PIGN). In the patient described here, immunological testing and the self-limiting course of the disease allowed for a non-invasive diagnosis of APSGN. The most likely, symptomatically treated upper respiratory tract infection was of streptococcal etiology.

Treatment of APSGN is purely symptomatic and involves monitoring fluid balance, body weight, blood pressure, and serum creatinine and potassium levels [2, 3, 17]. The dietary sodium intake should be limited, and in the case of a tendency to hyperkalemia also potassium should be limited. In overhydration, fluid restriction and loop diuretics (most commonly furosemide given at an initial dose of $1 \mathrm{mg} / \mathrm{kg}$ ) are used. In the treatment of hypertension, apart from loop diuretics, calcium channel antagonists may be used; drugs inhibiting the renin-angiotensin-aldosterone system ought to be used with caution due to the tendency to hyperkalemia and risk of exacerbating renal impairment [17]. In the present patient, hyperuricemia was successfully treated with rasburicase. Rasburicase, intended initially for the treatment of tumor lysis syndrome, was found to be effective and safe in children with AKI of different etiology, including hemolytic-uremic syndrome (HUS) [34, 35]. The authors' center is considering the use of rasburicase in any case of AKI with severe hyperuricemia (usually $>10 \mathrm{mg} / \mathrm{dl}$ ), and experience to date (mainly in patients with HUS) has been very promising.

Antibiotics are not routinely used in the treatment of APSGN. However, in the case of symptoms of active infection, an antibiotic covering the spectrum of GAS is administered - according to Polish recommendations, it should be phenoxymethylpenicillin administered for ten days at a dose of 100,000-200,000 IU/kg/day [36]. Some authors recommend antibacterial treatment even in the absence of features of active infection in order, among others, to reduce the risk of infection in household members [3]. The patient was started on ceftriaxone due to fever and very high inflammatory markers suggestive of sepsis. We did not detect a particular source or etiologic factor of the present infection, though physical examination revealed vulvitis and pharyngitis. We chose ceftriaxone following Surviving Sepsis Campaign international guidelines [37]. The patient presented with biliary deposits during the treatment. A recently published systematic review including 5717 pediatric patients who received ceftriaxone reported 1136 adverse drug reactions (ADRs). The most frequently reported ADRs were gastrointestinal disorders $(37.4 \%$, $292 / 780)$, followed by hepatobiliary disorders $(24.6 \%$, 192/780). Almost all cases of biliary pseudolithiasis were reversible; however, the incidence was surprisingly high, affecting one in five pediatric patients $(20.7 \%)$ [38]. Notably, the incidence of biliary pseudolithiasis might be even higher in patients with renal function impairment as drug biliary excretion rises in case of kidney insufficiency.

Although improved hygiene conditions and a decrease in the frequency of skin infections have reduced the incidence of APSGN in developed countries, there is still no clear evidence of a reduced risk of the disease after antibiotic treatment of streptococcal infections [2, 9]. In one Australian observational study, treatment of streptococcal infection with benzathine penicillin $\mathrm{G}$ was found to prevent new cases of glomerulonephritis [39]. Experimental data suggest that the widespread presence of fluoride in water decreases virulence factors of GAS and may also contribute to reduced APSGN prevalence in developed countries [40].

The prognosis in children with APSGN is generally excellent. The disease is self-limiting, and in most cases, renal function recovers entirely after the acute period. Long-term outcome studies in children with APSGN are scarce, but the overall prognosis is excellent. Persistent proteinuria, microalbuminuria, or hypertension is found in only $0.5-3 \%$ of patients. Isolated hematuria may persist the longest, sometimes up to two or even five years [2, 3, 17]. The risk for renal function impairment is very low, in most studies below 1\% [3]. Authors from Great Ormond Street Hospital recommend yearly follow-up after complete recovery to look for evidence of hypertension, proteinuria, or renal impairment [14].

\section{Conclusions}

In children, APSGN has an excellent prognosis, including in cases with severe renal impairment in the early stages of the disease.

\section{The authors declare no conflict of interest.}

\section{References}

1. Carapetis JR, Steer AC, Mulholland EK, et al. (2005): The global burden of group A streptococcal diseases. Lancet Infect Dis 5: 685-694.

2. Eison TM, Ault BH, Jones DP, et al. (2011): Post-streptococcal acute glomerulonephritis in children: clinical features and pathogenesis. Pediatr Nephrol 26: 165-180.

3. Rodriguez-Iturbe B, Musser JM (2008): The current state of poststreptococcal glomerulonephritis. J Am Soc Nephrol 19: $1855-1864$.

4. Coppo R, Gianoglio B, Porcellini MG, et al. (1998): Frequency of renal diseases and clinical indications for renal biopsy in children (report of the Italian National Registry of Renal Biopsies in Children). Group of Renal Immunopathology of the Italian Society of Pediatric Nephrology and Group of Renal Immunopathology of the Italian Society of Nephrology. Nephrol Dial Transplant 13: 293-7. 
5. Blyth CC, Robertson PW, Rosenberg AR (2007): Post-streptococcal glomerulonephritis in Sydney: a 16-year retrospective review. J Paediatr Child Health 43: 446-450.

6. Schwartz GJ, Muńoz A, Schneider MF, et al. (2009): New equations to estimate GFR in children with CKD. J Am Soc Nephrol 20: 629-637.

7. Cunningham MW (2000): Pathogenesis of group A streptococcal infections. Clin Microbiol Rev 13: 470-511.

8. Motoyama O, Hasegawa K, Okamatsu C, et al. (2004): Acute glomerulonephritis in three siblings and suspected emm49type Streptococcus pyogenes infection. Clin Exp Nephrol 8: 356-358.

9. Dillon HC, Jr. (1970): Streptococcal skin infection and acute glomerulonephritis. Postgrad Med J 46: 641-652.

10. Bakr A, Mahmoud LA, Al-Chenawi F, et al. (2007): HLADRB1* alleles in Egyptian children with post-streptococcal acute glomerulonephritis. Pediatr Nephrol 22: 376-379.

11. Becquet O, Pasche J, Gatti H, et al. (2010): Acute post-streptococcal glomerulonephritis in children of French Polynesia: a 3-year retrospective study. Pediatr Nephrol 25: 275-280.

12. Li Volti S, Furnari ML, Garozzo R, et al. (1993): Acute post-streptococcal glomerulonephritis in an 8-month-old girl. Pediatr Nephrol 7: 737-738.

13. Wiwanitkit V (2006): Why is acute post-streptococcal glomerulonephritis more common in the pediatric population? Clin Exp Nephrol 10: 164.

14. Balasubramanian R, Marks SD (2017): Post-infectious glomerulonephritis. Paediatr Int Child Health 37: 240-247.

15. Idhate T, Zaki SA, Shanbag P (2017): Cardiac status in children with acute poststreptococcal glomerulonephritis. Saudi J Kidney Dis Transpl 28: 830-835.

16. Adikari M, Priyangika D, Marasingha I, et al. (2014): Post-streptococcal glomerulonephritis leading to posterior reversible encephalopathy syndrome: a case report. BMC Res Notes 7: 644.

17. Ahn SY, Ingulli E (2008): Acute poststreptococcal glomerulonephritis: an update. Curr Opin Pediatr 20: 157-162.

18. Rodríguez-Iturbe B, Batsford S (2007): Pathogenesis of poststreptococcal glomerulonephritis a century after Clemens von Pirquet. Kidney Int 71: 1094-1104.

19. Burova L, Pigarevsky P, Seliverstova V, et al. (2012): Experimental poststreptococcal glomerulonephritis elicited by IgG Fc-binding $\mathrm{M}$ family proteins and blocked by $\mathrm{IgG} \mathrm{Fc}$ fragment. Apmis 120: 221-230.

20. Rodríguez-Iturbe B, Katiyar VN, Coello J (1981): Neuraminidase activity and free sialic acid levels in the serum of patients with acute poststreptococcal glomerulonephritis. $\mathrm{N}$ Engl J Med 304: 1506-1510.

21. Ardiles LG, Valderrama G, Moya P, et al. (1997): Incidence and studies on antigenic specificities of antineutrophil-cytoplasmic autoantibodies (ANCA) in poststreptococcal glomerulonephritis. Clin Nephrol 47: 1-5.

22. Vogt A, Schmiedeke T, Stöckl F, et al. (1990): The role of cationic proteins in the pathogenesis of immune complex glomerulonephritis. Nephrol Dial Transplant 5 Suppl 1: 6-9.

23. Yoshizawa N, Yamakami K, Fujino M, et al. (2004): Nephritis-associated plasmin receptor and acute poststreptococcal glomerulonephritis: characterization of the antigen and associated immune response. J Am Soc Nephrol 15: 1785-1793.

24. Oda T, Yoshizawa N, Yamakami K, et al. (2010): Localization of nephritis-associated plasmin receptor in acute poststreptococcal glomerulonephritis. Hum Pathol 41: 1276-1285.
25. Oda T, Tamura K, Yoshizawa N, et al. (2008): Elevated urinary plasmin activity resistant to alpha2-antiplasmin in acute poststreptococcal glomerulonephritis. Nephrol Dial Transplant 23: 2254-2259.

26. Cu GA, Mezzano S, Bannan JD, et al. (1998): Immunohistochemical and serological evidence for the role of streptococcal proteinase in acute post-streptococcal glomerulonephritis. Kidney Int 54: 819-826.

27. Batsford SR, Mezzano S, Mihatsch M, et al. (2005): Is the nephritogenic antigen in post-streptococcal glomerulonephritis pyrogenic exotoxin B (SPE B) or GAPDH? Kidney Int 68: 1120-1129.

28. Pérez-Caballero D, García-Laorden I, Cortés G, et al. (2004): Interaction between complement regulators and Streptococcus pyogenes: binding of $\mathrm{C} 4 \mathrm{~b}$-binding protein and factor $\mathrm{H} /$ factor $\mathrm{H}$-like protein 1 to M18 strains involves two different cell surface molecules. J Immunol 173: 6899-6904.

29. Demircioglu Kılıc B, Akbalık Kara M, Buyukcelik M, et al. (2018): Pediatric post-streptococcal glomerulonephritis: Clinical and laboratory data. Pediatr Int 60: 645-650.

30. West CD, McAdams AJ (1998): Serum and glomerular IgG in poststreptococcal glomerulonephritis are correlated. Pediatr Nephrol 12: 392-396.

31. Chauvet S, Berthaud R, Devriese M, et al. (2020): Anti-factor $\mathrm{B}$ antibodies and acute postinfectious GN in children. J Am Soc Nephrol 31: 829-840.

32. Mori K, Sasazuki T, Kimura A, et al. (1996): HLA-DP antigens and post-streptococcal acute glomerulonephritis. Acta Paediatr 85: 916-918.

33. Sen ES,Ramanan AV (2014): How to use antistreptolysin O titre. Arch Dis Child Educ Pract Ed 99: 231-238.

34. Hobbs DJ, Steinke JM, Chung JY, et al. (2010): Rasburicase improves hyperuricemia in infants with acute kidney injury. Pediatr Nephrol 25: 305-309.

35. Cho MH, Ahn YH, Lim SH, et al. (2020): Rasburicase improves the outcome of acute kidney injury from typical hemolytic uremic syndrome. Pediatr Nephrol 35: 2183-2189.

36. Sitkiewicz I, Hryniewicz W (2010): Pyogenic streptococci--danger of re-emerging pathogens. Pol J Microbiol 59: 219-26.

37. Weiss SL, Peters MJ, Alhazzani W, et al. (2020): Surviving sepsis campaign international guidelines for the management of septic shock and sepsis-associated organ dysfunction in children. Intensive Care Med 46: 10-67.

38. Zeng L, Wang C, Jiang M, et al. (2020): Safety of ceftriaxone in paediatrics: a systematic review. Arch Dis Child 105: 981985.

39. Johnston F, Carapetis J, Patel MS, et al. (1999): Evaluating the use of penicillin to control outbreaks of acute poststreptococcal glomerulonephritis. Pediatr Infect Dis J 18: 327-332.

40. Thongboonkerd V, Luengpailin J, Cao J, et al. (2002): Fluoride exposure attenuates expression of Streptococcus pyogenes virulence factors. J Biol Chem 277: 16599-16605. 